\title{
Goldilocks meets heparin dosing—enough but not too much
}

\author{
Jonathan R. Egan, MBBS, PhD, FRACP, FCICM, ${ }^{\text {,d }}$ Tatjana Kilo, FRCPA, ${ }^{\mathrm{b}}$ and \\ David S. Winlaw, MBBS, MD, FRACS ${ }^{\mathrm{c}, \mathrm{d}}$
}

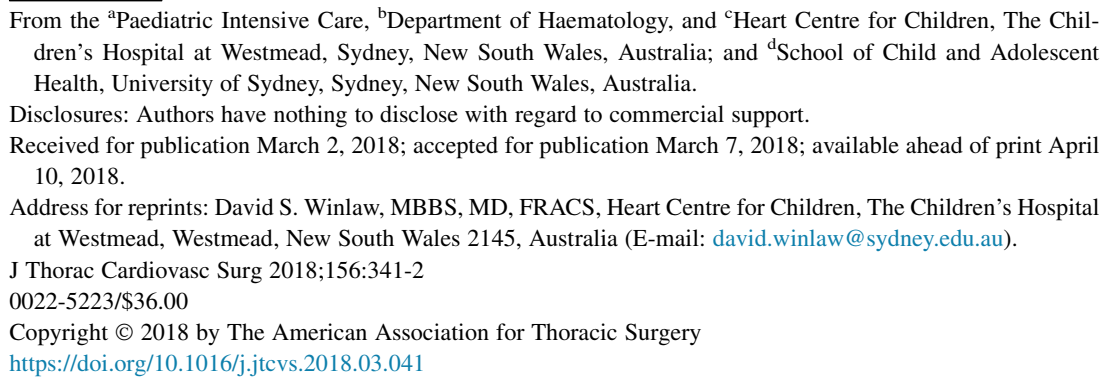

Sometimes the status quo is so deeply embedded, it is difficult to change practice without compelling evidence. In monitoring of anticoagulation, the superiority of anti-Xa levels over activated partial thromboplastin time (aPTT) is routinely advised. A more nuanced picture is provided by Oladunjoye and colleagues ${ }^{1}$ within the frame of postoperative cardiac care, emphasizing the role of aPTT in defining the risk of bleeding complications. Compelling? Yes.

A lack of correlation between APTT and anti-Xa in monitoring heparin levels has been shown in several pediatric studies, ${ }^{2}$ most elegantly by Newall and colleagues ${ }^{3}$ in a series of patients who received cardiac catheterization. Further, in a study of 39 patients, it was demonstrated that discordance between high aPTT and therapeutic range anti-Xa levels was associated with major bleeding events. ${ }^{4}$ Similar findings have been observed in adults, with the same pattern of discordance also found to be associated with worse outcomes. In a study of more than 500 patients, it was found that aPTT and anti-Xa levels were frequently discordant, with prolonged aPTT relative to anti-Xa the most common finding. This cohort had increased risks of significant bleeding and higher 30 -day mortality. ${ }^{5}$ Consequently, it was suggested to pragmatically use anti-Xa levels to provide an estimate of heparin concentration, whereas aPTT informed the background coagulation status and potential risk/benefit of anticoagulation. However, no specific algorithm was suggested, just that high aPTT, relative to anti-Xa, was an important risk.

Oladunjoye and colleagues ${ }^{1}$ proposed a guideline on the basis of their experience in a year-long single-center review of heparinized postoperative infants and children. It was found that important bleeding events were similarly associated with high aPTT levels and concurrently measured normal-range anti-Xa levels. This finding led to a change in practice in which heparin dosing was not escalated on the basis of anti-Xa levels if the aPTT exceeded

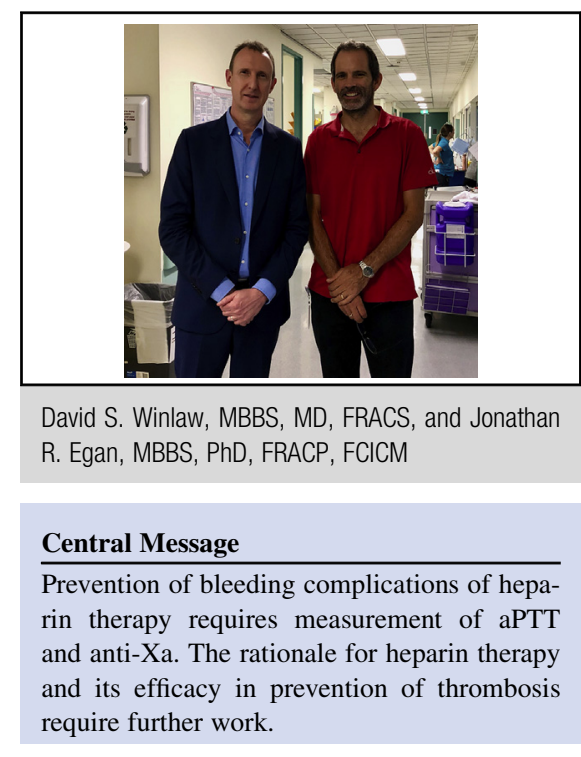

See Article page 332.

100 seconds. The algorithm is a pragmatic approach to heparin use in this patient group, noting that there was no routine surveillance for thrombosis and patients receiving extracorporeal life support were not included.

This work will improve the safety of heparin therapy but raises other questions about commonly accepted practices. We are left wondering what measure best defines the lower limit of effective anticoagulation and whether "effective" anticoagulation actually prevents thrombosis in our patients. Neonates with intra-atrial lines after Norwood surgery are at particular risk of thromboembolism, and sometimes thrombus forms despite adequate anticoagulation. ${ }^{6}$ Other practices, such as heparinizing patients after Fontan completion, also could be reconsidered, with diverse approaches seemingly yielding similar outcomes.

The original work describing use of aPTT and anti-Xa levels in the monitoring of anticoagulation stems from a report in 1972. ${ }^{7}$ Increased sophistication in this field will involve routine surveillance of thrombus, concurrent measurement of antithrombin III levels, and assessment of the dynamic contribution of dynamic clot formation with thromboelastography. It is understood that titration of heparin will never be a precise science. For now, this study provides 2 important practice pointers: Routinely measure both 
aPTT and anti-Xa, and do not escalate heparin dosing if the aPTT is 100 seconds or more.

\section{References}

1. Oladunjoye OO, Sleeper LA, Nair AG, Trenor CC, VanderPluym C, Kheir JN, et al. Partial thromboplastin time is more predictive of bleeding than anti-Xa levels in heparinized pediatric patients following cardiac surgery. J Thorac Cardiovasc Surg. 2018;156:332-40.e1.

2. Kuhle S, Eulmesekian P, Kavanagh B, Massicotte P, Vegh P, Lau A, et al. Lack of correlation between heparin dose and standard clinical monitoring tests in treatment with unfractionated heparin in critically ill children. Haematologica. 2007;92:554-7.

3. Newall F, Ignjatovic V, Johnston L, Summerhayes R, Lane G, Cranswick N, et al. Clinical use of unfractionated heparin therapy in children: time for change? $\mathrm{Br} J$ Haematol. 2010;150:674-8.
4. Kuhle S, Eulmesekian P, Kavanagh B, Massicotte P, Vegh P, Mitchell LG. A clinically significant incidence of bleeding in critically ill children receiving therapeutic doses of unfractionated heparin: a prospective cohort study. Haematologica. 2007;92:244-7.

5. Price EA, Jin J, Nguyen HM, Krishnan G, Bowen R, Zehnder JL. Discordant aPTT and anti-Xa values and outcomes in hospitalized patients treated with intravenous unfractionated heparin. Ann Pharmacother. 2013;47:151-8.

6. Verrall CE, Walker K, Loughran-Fowlds A, Prelog K, Goetti R, Troedson C, et al. Contemporary incidence of stroke (focal infarct and/ or haemorrhage) determined by neuroimaging and neurodevelopmental disability at 12 months of age in neonates undergoing cardiac surgery utilizing cardiopulmonary bypass. Interact Cardiovasc Thorac Surg. 2013;26: 644-50.

7. Basu D, Gallus A, Hirsh J, Cade J. A prospective study of the value of monitoring heparin treatment with the activated partial thromboplastin time. $N$ Engl J Med. 1972;287:324-7. 